$05 ; 14$

\title{
Эффект длины зонда на кантилевере атомно-силового микроскопа в измерениях механических свойств нативных нейронов
}

\author{
(C) А.В. Анкудинов ${ }^{1,2}$, М.М. Халисов ${ }^{2,3}$, В.А. Пеннияйнен ${ }^{3}$, \\ С.А. Подзорова ${ }^{3}$, К.И. Тимощук ${ }^{2,3}$, Б.В. Крылов ${ }^{3}$ \\ ${ }^{1}$ Физико-технический институт им. А.Ф. Иоффе РАН, Санкт-Петербург, \\ Россия \\ ${ }^{2}$ Санкт-Петербургский национальный исследовательский университет \\ информационных технологий, механики и оптики, Санкт-Петербург, \\ Россия \\ ${ }^{3}$ Институт физиологии им. И.П. Павлова РАН, Санкт-Петербург, Россия \\ E-mail: alexander.ankudinov@mail.ioffe.ru
}

Поступило в Редакцию 20 апреля 2018 г.

Методом атомно-силовой микроскопии в режиме PeakForce QNM в условиях, приближенных к физиологическим, исследовались нативные сенсорные нейроны. Выявлена зависимость измеряемого кажущегося модуля Юнга клеток от отношения высоты зонда к длине консоли используемого кантилевера. Дано качественное объяснение полученного результата, опирающееся на анализ деформаций консоли в двух крайних случаях: зонд скользит по объекту исследования, зонд защемлен последним. Предложено классифицировать нативные клетки по преобладающему характеру взаимодействия с зондом (скольжение или залипание).

DOI: 10.21883/PJTF.2018.15.46438.17351

Привлекательным приложением атомно-силовой микроскопии (АСМ) становятся исследования механических свойств, главным образом модуля Юнга, нативных клеток $[1,2]$. Представляет большой интерес определение влияния на клетку различных фармакологических веществ [3-5]. Недавно с помощью АСМ изучалось действие на нативные сенсорные нейроны веществ с анальгетическим эффектом. Был выявлен примерно полуторакратный рост модуля Юнга у исследуемых клеток при введении в культуральную среду уабаина [6,7]. У нейронов, 
культивируемых на разных подложках — поли-L-лизиновой и коллагенфибронектиновой, с помощью кантилеверов Bruker SNL-(D) и SNL(C) соответственно наблюдалась одинаковая реакция на уабаин. Однако абсолютные значения средних модулей Юнга у однотипных клеток расходились в этих двух случаях почти в 4 раза, что связывалось с вероятным влиянием на механические свойства клеток химического состава используемых подложек [7,8]. Возможная роль характеристик используемого кантилевера в таком расхождении не рассматривалась. Настоящая работа посвящена выяснению роли характеристик кантилевера в АСМ-измерениях модуля Юнга нативных клеток.

Исследовались нативные сенсорные нейроны 10-12-дневных куриных эмбрионов. Извлеченные из областей L5-S1 ганглии спинного мозга пипетировали в растворе Хенкса для получения суспензии клеток. Культивирование нейронов осуществлялось в питательной среде: раствор Хенкса - 45\%, среда Игла - 40\%, фетальная бычья сыворотка $15 \%$, инсулин $-0.5 \mathrm{U} / \mathrm{ml}$, глюкоза $-0.6 \%$, глютамин $-2 \mathrm{mM}$, гентамицин - $100 \mathrm{U} / \mathrm{ml}$, фактор роста нервов 7S - $10 \mathrm{ng} / \mathrm{ml}$ (Sigma, CША). Питательная среда добавлялась к полученной клеточной суспензии для получения желаемой плотности клеток в пластиковой чашке Петри. Ненейрональные клетки удаляли, позволяя им оседать на поверхности пластика 90-миллиметровой чашки Петри в течение $25 \mathrm{~min}$ при $37^{\circ} \mathrm{C}$ в $\mathrm{CO}_{2}$-инкубаторе (Sanyo, Япония), в то время как оставшиеся клетки (в основном нейроны) культивировали на покрытых поли-L-лизином поверхностях 40-миллиметровых чашек Петри в течение трех суток при $37^{\circ} \mathrm{C}$ в $5 \% \mathrm{CO}_{2}$.

Сенсорные нейроны в питательной среде исследовались с помощью атомно-силового микроскопа BioScope Catalyst (Bruker, США), интегрированного в оптический микроскоп Axio Observer Z1 (Carl Zeiss, Германия). АСМ-эксперименты проводились при температуре $37^{\circ} \mathrm{C}$, которая поддерживалась с помощью термоконтроллера Model 335 (Lake Shore Cryotronics, CШA). Применялось три типа кантилеверов: SNL-(D) и DNP-(C) (Bruker, CШA), NITRA-TALL-V-G-(A) (AppNano, CШA) (см. таблицу).

Измерения проводились в АCM-режиме PeakForce QNM со следующими параметрами сканирования: частота строчной развертки $0.10-0.15 \mathrm{~Hz}$, пиковая сила $1 \mathrm{nN}$, частота и амплитуда вертикального зондирования $0.25 \mathrm{kHz}$ и $1 \mu \mathrm{m}$ соответственно. Особенность режима заключается в поточечном измерении силовых, индентационных кривых и

Письма в ЖТФ, 2018, том 44, вып. 15 
Характеристики кантилеверов [9,10], использованных в АСМ-измерениях, и кажущиеся средние модули Юнга $E$ сенсорных нейронов на поли-L-лизиновой подложке $\left(k_{C}-\right.$ жесткость консоли, $l_{C}-$ длина консоли, $l_{T}-$ высота зонда, $r$ - радиус кончика зонда)

\begin{tabular}{c|c|c|c|c}
\hline \multirow{2}{*}{ Параметр } & \multicolumn{4}{|c}{ Марка } \\
\cline { 2 - 5 } & SNL-(D) & SNL-(C) & DNP-(C) & NITRA-TALL-V-G-(A) \\
\hline$k_{C}, \mathrm{~N} / \mathrm{m}$ & $0.03-0.12$ & $0.12-0.48$ & $0.12-0.48$ & $0.08-0.32$ \\
& $\left(0.07^{*}\right)$ & $\left(0.32^{*}\right)$ & $\left(0.25^{*}\right)$ & $\left(0.21^{*}\right)$ \\
$l_{C}, \mu \mathrm{m}$ & $200-210$ & $115-125$ & $115-125$ & $95-115$ \\
$l_{T}, \mu \mathrm{m}$ & $2.5-8.0\left(4^{* *}\right)$ & $2.5-8.0\left(4^{* *}\right)$ & $2.5-8.0\left(5^{* *}\right)$ & $14-16\left(15^{* *}\right)$ \\
$r, \mathrm{~nm}$ & $2-12$ & $2-12$ & 20 & $<30$ \\
Материал зонда & Кремний & Кремний & Нитрид & Китрид \\
$E, \mathrm{kPa}$ & 115 & $31^{* * *}$ & 22 & кремния \\
& & & & 11
\end{tabular}

* Среднее значение жесткости кантилевера, измеренное методом тепловых шумов.

** Средняя высота зонда, измеренная в оптическом микроскопе через объектив с $\mathrm{NA}=0.9$.

*** Среднее значение кажущегося модуля Юнга сенсорных нейронов на коллагенфибронектиновой подложке [6].

последующей автоматической обработке получаемого массива данных. Силовые кривые анализировались в рамках модели Снеддона [11] с помощью зависимости

$$
F=E \frac{2 \tan \theta}{\pi\left(1-v^{2}\right)} \delta^{2},
$$

где $F-$ сила взаимодействия зонд-образец, $v-$ коэффициент Пуассона $(v=0.5), \theta=18^{\circ}$ - полуугол раствора конуса, аппроксимирующего пирамидальную форму зонда, $\delta$ - глубина деформации. Значение $E$, оптимизирующее подгонку кривой (1) к эксперименту, соответствует кажущемуся модулю Юнга [12]. 2D-карта значений $E$ на участке подложки с сенсорным нейроном изображена на рис. 1, $a$. Из области изображения, соответствующей соме клетки, извлекался массив данных, который преобразовывался в частотное распределение параметра с шагом $5 \mathrm{kPa}$. Результаты, полученные с помощью разных кантилеверов, сравнивались по средним распределениям кажушегося модуля Юнга по выборкам клеток. 
Данные исследования нативных сенсорных нейронов при применении АСМ-кантилеверов трех типов анализируются на рис. $1, b$. Видно, что значения кажущихся модулей Юнга не совпадают. Положения пиков распределения параметра $E$ для кантилеверов Bruker SNL-(D), DNP-(C) и AppNano NITRA-TALL-V-G-(A) приходятся на 32, 12 и $7 \mathrm{kPa}$; средние значения $115 \pm 90,22 \pm 10$ и $11 \pm 7 \mathrm{kPa}$ соответственно (см. таблицу).

Данные рис. 1 достоверно демонстрируют несовпадение средних значений $E$, полученных с помощью кантилеверов трех типов. $U$-критерий Манна-Уитни подтвердил значимость различий (у любой из трех возможных пар статистическая разница $p<0.01)$.

В таблице сопоставлены характеристики использованного кантилевера с измеренным с его помощью результатом. Например, нет явной корреляции величины $E$ с материалом зонда и с жесткостью консоли. Можно заметить, что значение $E$ больше у острых зондов. Эта связь могла бы быть важной, если бы индентирование проводилось на глубину меньше радиуса кривизны. В наших же измерениях глубина составляла несколько сотен нанометров, и площадь контакта практически не зависела от остроты кончика. Это обосновывало вычисления модуля Юнга по формуле (1), в которую радиус кривизны не входит. Наиболее существенной представляется зависимость величины $E$ от отношения длины консоли к высоте зонда. Приведем объяснение этой зависимости.

Как в большинстве современных атомно-силовых микроскопов, в Bruker BioScope Catalyst использована система оптического рычага [13], следящая не за смещениями зонда, а за углами отклонения (изгиба или кручения) консоли, несущей зонд. Поскольку углов два, все три компоненты вектора смещения зонда или силы взаимодействия не определяются однозначно $[14,15]$, что усложняет интерпретацию измерений. Рис. 2 иллюстрирует два крайних случая реакции кантилевера на поднятие образца: трения нет, зонд скользит по образцу, консоль изгибается, угол отклонения монотонно растет от точки закрепления к концу консоли (рис. 2,a); трение есть, зонд защемился на образце, консоль прогибается, угол отклонения в начале растет, а в конце убывает (рис. 2,b). Защемление зонда приводит к меньшим углам отклонения конца консоли, чем его скольжение при таком же поднятии образца. Из-за этого регулируемый системой обратной связи АСМ угол отклонения консоли будет при защемлении зонда достигаться при большем перемещении и, как следствие, большей деформации образца,

Письма в ЖТФ, 2018, том 44, вып. 15 

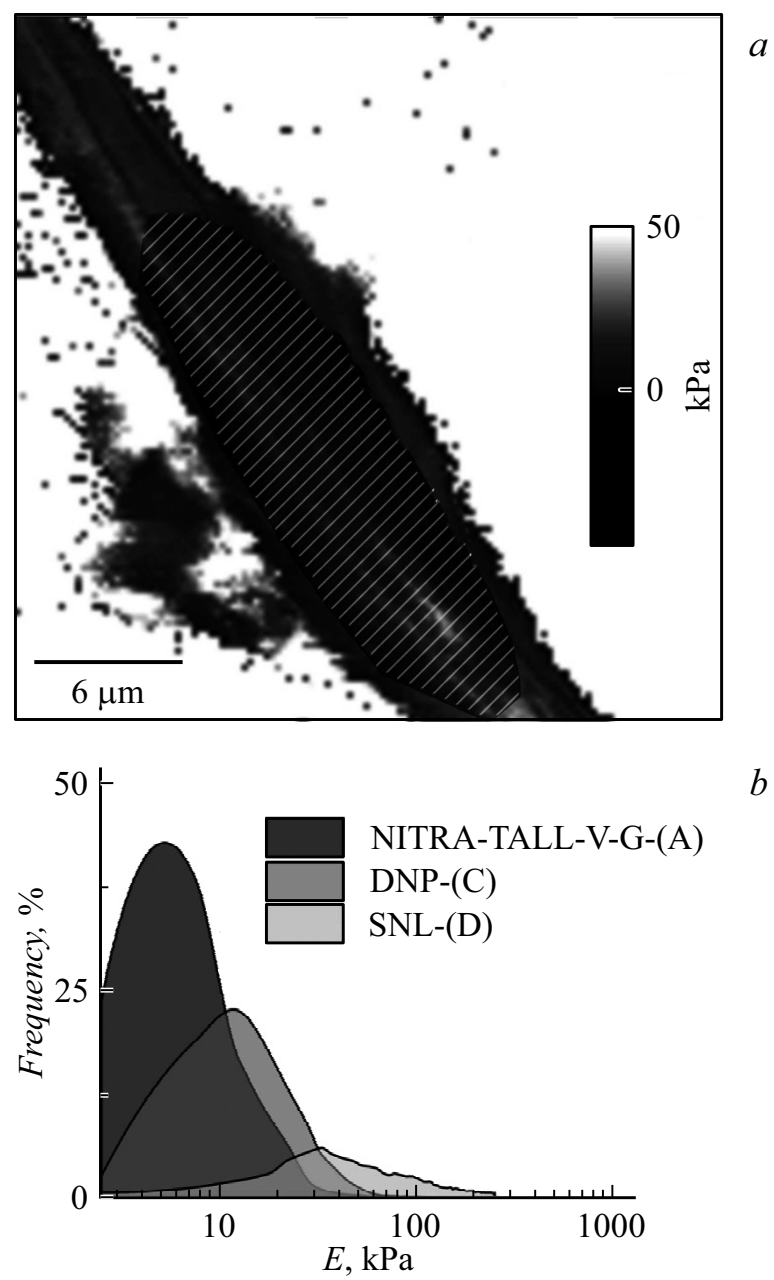

Рис. 1. $a-$ АCМ-карта параметра $E$ на участке подложки с нативным сенсорным нейроном, заштрихована область выборки - сома клетки; $b-$ распределение средних значений $E$ по сомам нейронов при применении кантилеверов NITRA-TALL-V-G-(A), DNP-(C) и SNL-(D). В каждом случае исследовано $n=21,18$ и 30 нейронов соответственно.

Письма в ЖТФ, 2018, том 44, вып. 15 

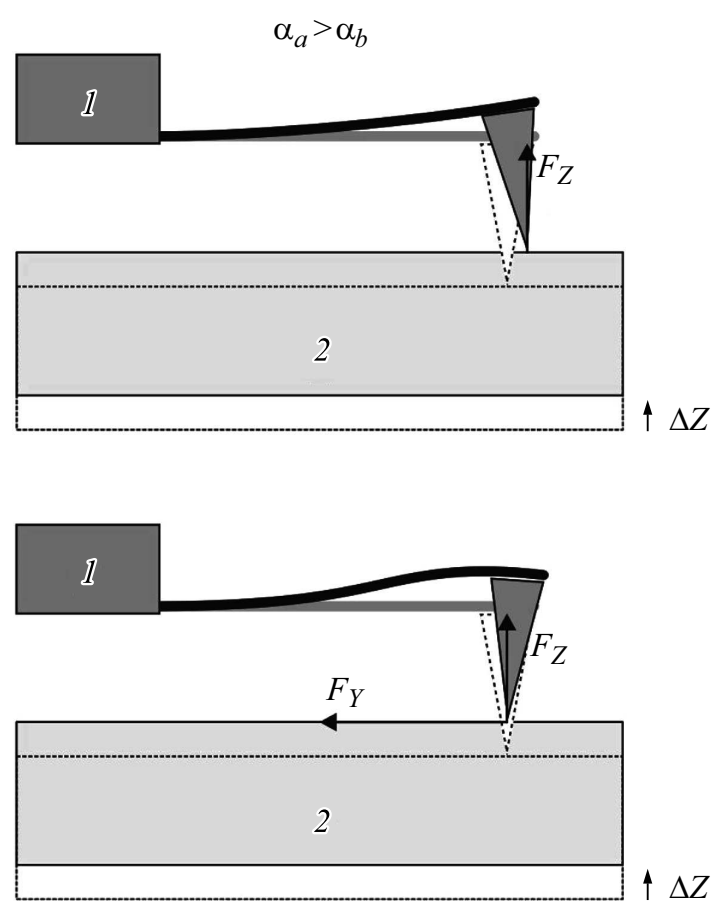

$b$

Рис. 2. Качественное объяснение результатов измерений. Деформация консоли кантилевера при поднятии образца на высоту $\Delta Z: a-$ в условиях скользящего контакта (трения нет, действует только нормальная сила $F_{Z}$ ), угол изгиба на конце консоли $\alpha_{a} ; b$ - заостренный зонд защемился на образце (добавилась латеральная сила $F_{Y}$ ), угол прогиба на конце консоли $\alpha_{b} .1-$ чип с кантилевером, 2 - образец.

чем при скольжении. Другими словами, образец будет казаться мягче, чем при скольжении.

Угол отклонения конца консоли связан с силой противодействия, лежащей в плоскости рис. 2, следующим образом [16]:

$$
\alpha=\frac{3}{2 l_{C} k_{C}}\left(F_{Z}-2 \lambda F_{Y}\right)=\frac{3 F_{Z}}{2 l_{C} k_{C}}(1-2 \mu \lambda),
$$

где $\lambda=l_{T} / l_{C}-$ отношение высоты зонда к длине консоли, $k_{C}-$ коэффициент жесткости кантилевера, $\mu-$ отношение латеральной

Письма в ЖТФ, 2018, том 44, вып. 15 
компоненты силы к нормальной. Если зонд не скользит по поверхности образца $(\mu>0)$, то, согласно (2), угол $\alpha$ убывает с ростом $\lambda$. Поэтому чем больше $\lambda$ кантилевера, тем ниже значение $\alpha$ и, как следствие, контактная жесткость и кажущийся модуль Юнга образца. Качественно именно это и наблюдается в эксперименте (см. таблицу). Возможен и количественный анализ, учитывающий угол наклона чипа с кантилевером (в использованной АСМ-системе он равен $12^{\circ}$ ) и значения нормальной и латеральной жесткости контакта зонда с образцом. Его изложение имеет уточняющий характер и выходит за рамки представляемого краткого сообщения. Необходимо добавить, что отмеченное выше почти четырехкратное уменьшение кажущегося модуля Юнга нейронов, весьма вероятно, было вызвано не разным химическим составом подложек, а двукратным ростом величины $\lambda$ у кантилевера Bruker SNL-(C) по сравнению со значением для SNL-(D).

Таким образом, обнаружено, что измеряемый в ACM-режиме PeakForce QNM кажущийся модуль Юнга $E$ нативных клеток может зависеть от параметра $\lambda$ - отношения высоты зонда к длине консоли используемого кантилевера. Для сенсорных нейронов $E$ уменьшается с ростом $\lambda$, что указывает на залипание зонда на клетке при получении силовых кривых. Если зонд скользит по объекту, то вклад от $\lambda$ мал, и $E$ может служить количественным параметром. Если нет, то, изучая с помощью АСМ роль различных факторов в механических свойствах нативных клеток, необходимо не менять марку кантилевера. В заключение важно отметить, что, исследуя зависимости $E$ от $\lambda$, можно сортировать клетки по группам: липкие и скользкие по отношению к материалу зонда.

Работа выполнена при финансовой поддержке Программы фундаментальных научных исследований государственных академий наук на 2013-2020 гг. (ГП-14, раздел 64), а также РФФИ (грант № 18-015-00079).

\section{Список литературы}

[1] Kuznetsova T.G., Starodubtseva M.N., Yegorenkov N.I., Chizhik S.A., Zhdanov R.I. // Micron. 2007. V. 38. N 8. P. 824-833.

[2] Li M., Dang D., Liu L., Xi N., Wang Y. // IEEE Trans Nanobiosci. 2017. V. 16. N 6. P. 523-540. 
[3] Rotsch C., Radmacher M. // Biophys. J. 2000. V. 78. N 1. P. 520-535.

[4] Li M., Liu L.Q., Xi N., Wang Y.C. // Acta Pharmacol. Sin. 2015. V. 36. N 7. P. 769-782.

[5] Hung M.-Sh., Tsai M.-F. // BioNanoSci. 2015. V. 5. N 3. P. 156-161.

[6] Анкудинов А.В., Халисов М.М., Пеннияйнен В.А., Подзорова С.А., Крылов Б.В. // ЖТФ. 2015. Т. 85. В. 10. С. 126-130.

[7] Халисов М.М., Пеннияйнен В.А., Есикова Н.А., Анкудинов А.В., Крылов Б.В. // Письма в ЖТФ. 2017. Т. 43. В. 1. С. 89-94.

[8] Takai E., Costa K.D., Shaheen A., Hung C.T., Guo X.E. // Ann. Biomed. Eng. 2005. V. 33. N 7. P. 963-971.

[9] www.brukerafmprobes.com

[10] www.appnano.com

[11] Sneddon I. // Int. J. Eng. Sci. 1965. V. 3. N 1. P. 47-57.

[12] Costa K.D., Yin F.C. // J. Biomech. Eng. 1999. V. 121. N 5. P. 462-471.

[13] Meyer G., Amer N.M. // Appl. Phys. Lett. 1988. V. 53. N 12. P. 1045-1047.

[14] Fujisawa S., Ohta M., Konishi T., Sugawara Y., Morita S. // Rev. Sci. Instrum. 1994. V. 65. N 3. P. 644-647.

[15] Kawakatsu H., Bleuler H., Saito T., Hiroshi K. // Jpn. J. Appl. Phys. 1995. V. 34. N 6B. P. 3400-3402.

[16] Sarid D. Exploring scanning probe microscopy with MATHEMATICA. 2nd ed. Weinheim: Wiley-VCH, 2007. Ch. 2. P. 46.

Письма в ЖТФ, 2018, том 44, вып. 15 